\title{
Review \\ Is there a feudal hierarchy amongst regulatory immune cells? More than just Tregs
}

\author{
Claudia Mauri and Natalie Carter
}

Centre for Rheumatology Research, University College London, Department of Medicine, Cleveland Street, W1 4JF, UK

Corresponding author: Claudia Mauri, c.mauri@ucl.ac.uk

Published: 4 August July 2009

This article is online at http://arthritis-research.com/content/11/4/237

(c) 2009 BioMed Central Ltd
Arthritis Research \& Therapy 2009, 11:237 (doi:10.1186/ar2752)

\begin{abstract}
Nature has provided the developing immune system with several checkpoints important for the maintenance of tolerance and the prevention of autoimmunity. The regulatory mechanisms operating in the periphery of the system are mediated by subsets of regulatory cells, now considered principal contributors to peripheral tolerance. Regulatory $T$ cells (Tregs) have received titanic interest in the past decade, placing them at the centre of immunosuppressive reactions. However, it has become clearer that other immune suppressive cells inhibit auto-reactivity as effectively as Tregs. The function of Tregs and other regulatory cells in rheumatoid arthritis will be discussed in this review.
\end{abstract}

\section{Introduction}

Rheumatoid arthritis (RA) is an autoimmune disorder characterized by chronic systemic and synovial tissue inflammation that, if not therapeutically tackled, ultimately leads to bone and cartilage destruction. Like other autoimmune diseases, RA results from a cascade of reactions, beginning with the breakdown of tolerance and leading to dysregulated chronic inflammation in one or multiple organs [1]. During synovial inflammation, critical events include neoangiogenesis, cellular hyperplasia, and a massive influx of inflammatory cells such as T cells, B cells, fibroblast-like synoviocytes, macrophages, and dendritic cells (DCs). Cellular infiltration, and subsequent cellular proliferation, is largely orchestrated by a complex interplay of pro-inflammatory cytokines, chemokines, and matrix metalloproteinases $[1,2]$. In addition to expressing a variety of pro-inflammatory cytokines, the joint hosts immunosuppressive cells producing antiinflammatory cytokines (that is, IL-10 and transforming growth factor (TGF) $\beta$ ) [3]. The balance between the various regulatory $\mathrm{CD}^{+} \mathrm{T}$ cell subsets, collectively termed regulatory $\mathrm{T}$ cells (Tregs), IL-10-producing regulatory B cells (Bregs), regulatory DCs and suppressive macrophages on the one hand, and pro-inflammatory effector lymphocytes and monocyte-derived cells on the other, is likely to dictate the choice between tolerance and autoimmunity. In this review we have collated data from models that demonstrate the existence of different regulatory cells to generate a more unified view of how immunoregulatory cells may cooperate in the choice between maintenance and breakdown of tolerance in chronic inflammation.

\section{Regulatory cells: is there only one immunoregulatory queen? Regulatory $T$ cells} Regulatory CD4+ $\mathrm{T}$ cells can be divided into two main subsets, natural Tregs (nTregs) and induced Tregs (iTregs), which develop in the thymus and the periphery, respectively. nTregs express the transcription factor forkhead box protein 3 (FoxP3) during development in the thymus [4]. FoxP3 plays a key role in a sophisticated developmental program that nudges the immature $\mathrm{T}$ cell lineage into a regulatory pathway during positive selection on high affinity $T$ cell receptor ligands [4]. Via the $\mathrm{T}$ cell receptor, activated Tregs can exert non-antigen specific bystander suppression of other T cells [5]. Tregs have been shown to require cell-to-cell contact to suppress target cells in vitro [6]. Binding of CTLA-4 on Tregs to CD80 and CD86 on effector T cells (Teffs), infusion of cyclic AMP through gap junctions or direct cytolic mechanisms have been reported to be involved in Treg-mediated suppression [7]. In addition, Treg expression of glucocorticoid-induced tumour necrosis factor receptor (GITR) and Neuropillin-1 facilitate cell contact-mediated suppression of non-T cells such as endothelial cells and antigen-presenting cells (GITR) or DCs (Neuropillin-1) [8,9]. Efficient regulatory function requires an initial burst, followed by consumption, of endogenous IL-2 followed by the release of other soluble factors such as IL-10 and/or TGF $\beta$ and IL-35 [10-13].

Breg = regulatory $\mathrm{B}$ cell; $\mathrm{ClA}=$ collagen-induced arthritis; $\mathrm{Cll}=$ type $\|$ collagen; $\mathrm{DC}=$ dendritic cell; EAE = experimental autoimmune encephalomyelitis; FoxP3 = forkhead box protein 3; GITR = glucocorticoid-induced tumour necrosis factor receptor; IFN= interferon; IL = interleukin; $\mathrm{iTreg}=$ induced Treg; LAP = latency-associated peptide; MHC = major histocompatibility; $\mathrm{nTreg}=$ natural Treg; RA = rheumatoid arthritis; ROS = reactive oxygen species; T2-MZP $=$ transitional 2-marginal zone precursor; Teff $=$ effector $\mathrm{T}$ cell; TGF $=$ transforming growth factor; TNF $=$ tumour necrosis factor; Treg $=$ regulatory $\mathrm{T}$ cell; $\mathrm{VIP}=$ vasoactive intestinal peptide. 
Unlike FoxP3 ${ }^{+}$nTregs, which are fully functional upon thymic exit, iTregs are generated from naïve $\mathrm{CD}^{+} \mathrm{T}$ cells in the periphery, where they acquire suppressive capacity [14]. iTRegs can acquire the expression of FoxP3 (FoxP3+ iTregs) in response to antigens presented on non-inflammatory antigen-presenting cells coupled to TGF $\beta$ and IL-2. FoxP3 ${ }^{+}$ iTregs also require Foxp3 for their suppressive activity and phenotypic stability $[7,14]$. Data from several studies support the notion that iTregs are as important as nTregs in peripheral tolerance. In mice, FoxP3+ iTregs effectively control experimental autoimmune encephalomyelitis (EAE), colitis and type 1 diabetes [15-17]. Early thymectomised mice display impaired nTreg development but normal Foxp3 ${ }^{+}$iTreg numbers, and these mice develop a less severe disease than Foxp3deficient mice, suggesting that, early in life, iTreg cells may be vital due to the delay in nTreg development [18]. In addition, the foetal peripheral adaptive immune system generates FoxP3 ${ }^{+}$iTregs, in response to cross placenta maternal cells, that inhibit anti-maternal immunity. These iTregs persist at least into early adulthood [19]. iTregs are also important in adult life as they have been identified in situ and positively correlate with a clinical improvement of allergy symptoms [20]. Nonetheless, it remains difficult to dissect the relative contributions of iTregs and nTregs in the maintenance of tolerance, since once in the periphery they are phenotypically undistinguishable.

FoxP3- iTregs can be identified based on their specific cytokine profile, producing only IL-10 and/or TGF $\beta[21,22]$. FoxP3- iTregs display a low proliferative capacity and inhibit the development of both Th1-mediated experimental autoimmune diseases and Th2-mediated allergy [21,23]. They are induced in vitro and in vivo by sustained stimulation with IL-10, immature DCs or a combination of vitamin D3 and dexamethasone [24,25]. FoxP3- iTregs also include TGF $\beta$ producing Th3 cells and $\mathrm{CD} 4{ }^{+} \mathrm{CD} 25$ - latency-associated peptide $(\mathrm{LAP})+\mathrm{T}$ cells, which are central in mediating oral tolerance [26]. Th3 regulatory cells depend on IL-2 for survival and exert suppression primarily via TGF $\beta$, but also via IL-10 $[27,28]$. LAP ${ }^{+}$CD4 ${ }^{+}$CD25- $T$ cells are important in the inhibition of diabetes and colitis, and suppression is TGF $\beta$ dependent but IL-10-independent [21,29].

Other lymphocytes, including $\mathrm{CD}^{+}{ }^{+} \mathrm{FoxP}^{+}$cells, $\gamma \delta$ and invariant natural killer T cells are immunosuppressive [30-32], but since their functions in RA remain largely elusive they have not been included in this review.

\section{Regulatory cells in human rheumatoid arthritis and in experimental arthritis}

The first clues that Tregs are critical in mediating protection from arthritis were provided by the observations that depletion of $\mathrm{CD} 4^{+} \mathrm{CD} 25^{+}$cells in a collagen-induced arthritis (CIA) model, which closely mimics RA, resulted in increased severity and incidence of CIA [33] and that adoptive transfer of $\mathrm{CD}^{+}{ }^{+} \mathrm{CD} 25^{+}$cells in the early stages of disease slowed
CIA progression [34]. The transferred Tregs migrated to the arthritic joint where they acted locally to reduce inflammation [34]. However, it could not be definitively concluded that exacerbation of the disease seen following depletion of CD $4{ }^{+} \mathrm{CD} 25^{+}$cells was exclusively due to Treg depletion, as it may also be a result of the depletion of other regulatory CD25+-expressing cells, such as CD8 ${ }^{+} \mathrm{T}$ cells, Tr1, or Bregs [35]. Several other studies, using a variety of experimental models for arthritis, have now confirmed the importance of Tregs in 'dampening' arthritogenic responses [36-38] and their relevance in the maintenance of a 'stable' non-immunogenic environment.

Translation of data from experimental models to patients with RA has proved to be challenging. Our laboratory originally reported that Tregs are dysfunctional in RA as they cannot suppress tumour necrosis factor (TNF) $\alpha$ and interferon (IFN) $\gamma$ released by responder $\mathrm{CD}^{+} \mathrm{T}$ cells [39]. We and others have also described that therapies that target TNF $\alpha$, such as infliximab, increase the percentage of Tregs in circulation, and that Tregs isolated from patients responding to anti-TNF $\alpha$ therapy reacquire suppressive capacity $[39,40]$. Valencia and colleagues [40] elegantly demonstrated that TNF $\alpha$ directly suppresses human Tregs via signalling through TNF receptor II and inhibition of FoxP3 transcription. van Amelsfort and colleagues [41] have also shown that Tregs cultured with pro-inflammatory cytokines lose their capacity to inhibit responder $\mathrm{T}$ cell proliferation and cytokine production. However, paradoxically, TNF $\alpha$ is a potent immuno-modulator of CD4 ${ }^{+} \mathrm{T}$ cells and can, in some cases, prevent experimental autoimmune diseases such as type I diabetes and lupus [42,43]. In addition, TNF receptor II is chiefly expressed on both human and murine Tregs and is associated with higher suppressive capacity $[44,45]$. The dual functions of TNF $\alpha$ suggest that the mechanisms driving the induction of Tregs after TNF $\alpha$ blockade have not been completely elucidated.

Equally, the data relating to Treg number and function in RA are a complex jigsaw that remains to be assembled. In contrast to the lack of inhibition exerted by Tregs identified as CD $4^{+} \mathrm{CD} 25^{\text {high }}$ and isolated from peripheral blood, other studies have shown that CD4+CD25+ Tregs isolated from joints of patients with active arthritis had a more powerful suppressor activity than peripheral CD4 ${ }^{+}$CD $25^{+}$Tregs [46]. There is a disparity between the number of Tregs found in the peripheral blood of RA patients compared to the numbers of Tregs isolated from the joint of the same individuals, with more Tregs in the inflamed joints than in circulation, suggesting that compensatory mechanisms take place at the site of inflammation $[46,47]$. The discordance between different studies could be due to different methods of Treg purification (inclusion of all CD25 [46] versus the inclusion of only CD4 ${ }^{+}$CD25 high $T$ cells [39]) and/or a difference between the choices of the patients enrolled in each study. Whereas in our study only patients who failed all the conventional 
treatments and, hence, had more active RA were assessed, RA patients with a broader range of clinical scores were included in the van Amelsfort study $[39,41]$. These results suggest that the overall degree of inflammation, the balance between pro- and anti-inflammatory cells and the amount of cytokines they produce might influence Treg suppressive capacity.

$\mathrm{CD}^{+} \mathrm{T}$ cells producing IL-17 (Th17) play a pivotal role in the induction of arthritic diseases and should also be included in this complex 'balancing equation' $[48,49]$. Aberrant Th17 responses have been found in several experimental autoimmune models, including CIA [50] and EAE [51]. Patients with juvenile idiopathic arthritis displayed an increased number of $\mathrm{IL}-17^{+}$cells in both their synovial fluid and peripheral blood compared to the numbers in the peripheral blood of healthy volunteers [52]. It has been recently reported that disease severity in juvenile idiopathic arthritis is positively correlated with the numbers of Th17 cells and inversely correlated with Treg number, although not with their function, suggesting that the balance of Th17 cells and Tregs may be critical for disease outcome [52]. At the moment it remains to be formally proven whether functionally active Tregs can limit Th17 expansion or whether an uncontrolled Th17 expansion observed in patients with RA is responsible for the lack of Treg suppression.

The first evidence for the existence of IL-10-producing CD4 ${ }^{+}$ T cells in inflamed synovia was provided in 1994 by Feldman and collaborators [53], who showed that IL-10 was spontaneously produced in most synovial tissues isolated from RA patients. The major producers of $\mathrm{IL}-10$ were $\mathrm{T}$ cells in the mononuclear cell aggregates and monocytes in the lining layer. The authors also showed that neutralization of endogenously produced IL-10 in the RA synovial membrane cultures resulted in increased levels of the pro-inflammatory cytokines TNF $\alpha$ and IL-1 $\beta$, thus demonstrating the active antiinflammatory role of IL-10.

The discovery of new and more specific markers has allowed better discrimination of the various Treg subsets in vivo. Comprehensive studies comparing different Treg subsets should be carried out in the same cohorts of patients to give an overview of how the inflammatory environment influences all Treg responses in patients with RA. Fundamentally, a more 'holistic' approach should be considered for shaping future therapies as it is likely that the effect of anti-inflammatory cytokines released by Tregs, such as IL-10 and TGF $\beta$, is antagonised by the myriad pro-inflammatory factors present in the synovia. Perfusion of Tregs is unlikely to provide a long standing clinical benefit to patients with active autoimmune disease unless the pro-inflammatory environment is reconditioned to a 'neutral state', where Tregs can effectively maintain tolerance rather than re-condition existing inflammation (Figure 1).

\section{Are other immune regulatory cells the 'vassals' of regulation? \\ Regulatory B cells}

Traditionally, B cells have been seen as antibody secreting 'machines', but recently their capacity to produce distinct arrays of cytokines during chronic inflammation has been explored. Several groups have described B cells with regulatory function (Bregs) that can restrain immune responses and prevent autoimmune diseases, including arthritis $[35,54]$. Bregs were originally identified by Charles Janeway, who showed that B cell-deficient mice immunized with myelin basic protein in complete Freund's adjuvant were unable to recover from EAE [55]. These original data were confirmed and extended by Fillatreau and colleagues [56], who revealed that resolution of disease depends upon the presence of IL-10-producing B cells. Further, we have demonstrated that in vitro activation of arthritogenic $B$ cells with an agonistic anti-CD40 induces the differentiation of IL-10-producing B cells. When adoptively transferred, these activated B cells can control CIA development via the suppression of the autoreactive Th1 response [57]. These results were consistent with the inhibition of the spontaneous Th1 response of Palmerston North mice with lupus-like disease after the adoptive transfer of CpG-activated IL-10-producing B cells [58]. In addition, it has been reported that treatment of DBA/1 mice with apoptotic cells at the time of immunization with collagen type II (CII) suppresses Th1 differentiation and antibody production, and protected mice from arthritis via the induction of IL-10+ Bregs [59].

Unlike the Treg field, there is a lack of overall consensus about the combinations of markers that identify Bregs. We recently demonstrated that the $\mathrm{IL}-10^{+} \mathrm{B}$ cells in the CIA model are confined within the immature transitional 2marginal zone precursor (T2-MZP) B cell subset and are CD19+, CD21 high, CD23 high, CD24high and CD1dhigh [60]. Adoptive transfer of T2-MZP $B$ cells from naïve or convalescent mice prevented the recipient syngenic DBA 1 mice from developing arthritis. Although the mechanism of action of these T2-MZP Bregs has not been completely elucidated, we demonstrated that the protection is IL-10mediated, since T2-MZP B cells isolated from IL-10 knockout mice failed to protect against the Th1-driven autoimmune response in recipient mice. Analysis of $T$ cells isolated from T2-MZP B cell-treated mice revealed a reduction in proliferation following in vitro Cll stimulation, confirming that Bregs can reduce autoreactive $\mathrm{T}$ cell responses [60]. Unlike other autoimmune models, depletion of Tregs using anti-CD25 antibodies did not alter the capacity of Bregs to suppress arthritis, suggesting that Bregs, at least in $\mathrm{ClA}$, are not dependent on natural Tregs for their suppressive effects.

We have also identified $B$ regs with similar phenotype (T2-MZP) in the MRL/lpr mice lupus-like disease model, and demonstrated that they can be enriched upon short term in vitro culture with agonistic anti-CD40 [61]. Transfer of anti- 
(a) Resolution of joint inflammation

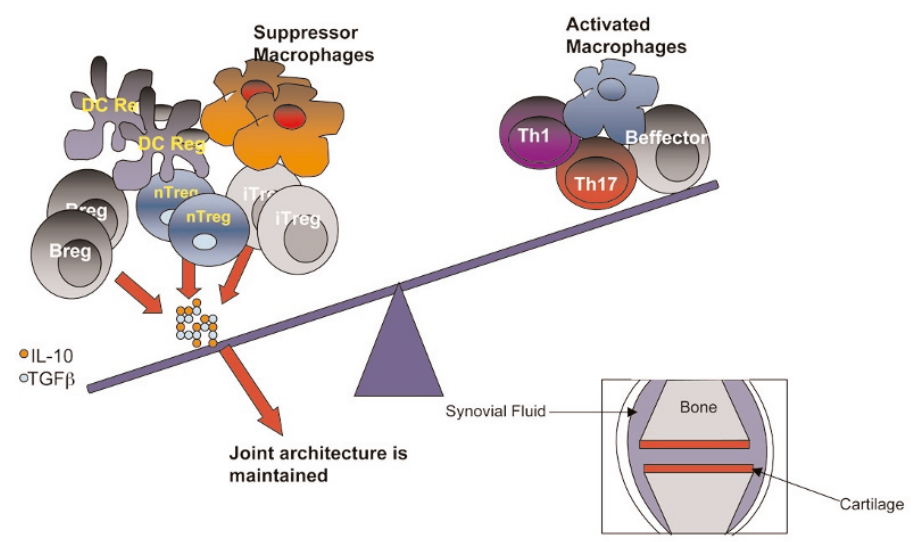

(b) Joint inflammation

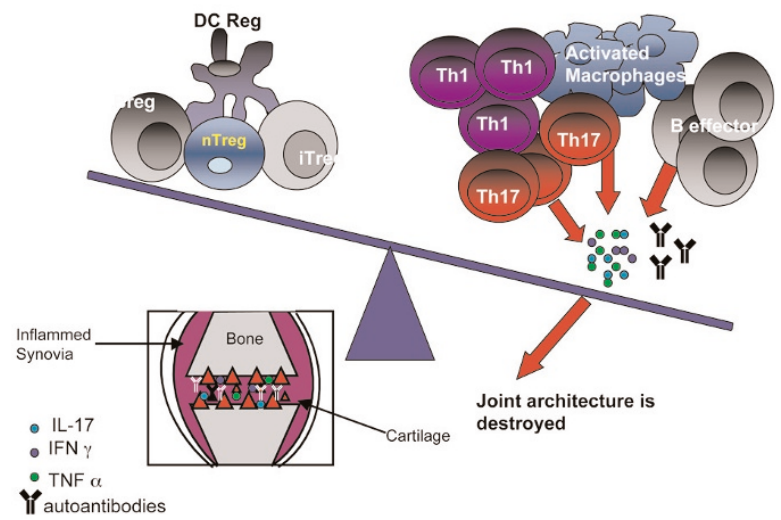

The balance between pro- and anti-inflammatory cell types and cytokines dictates arthritic disease development. (a) During inflammation the joint is overwhelmed by an influx of pro-inflammatory cell types. This activates the immune cells such as macrophages already present in the joint and results in a massive increase in pro-inflammatory cytokines, including IL-17, IL-1 $\beta$, IFN $\gamma$ and tumour necrosis factor (TNF) $\alpha$. Even though regulatory cells can be identified in arthritic joints, it is likely that the pro-inflammatory environment is over-powering and so renders these cells unable to suppress. This results in the joint architecture being destroyed and the synovia becoming inflamed. (b) Regulatory cell types that secrete antiinflammatory cytokines, including IL-10 and transforming growth factor (TGF) $\beta$, are in control of the resolution of joint inflammation in a nonautoimmune individual. This prevents the activation of the Th1 response, antibody production, effector B cell commitment and macrophage activation and so precludes damage to the joint architecture. Breg, regulatory B cell; DC, dendritic cell; IFN, interferon; IL, interleukin; iTreg, induced Treg; nTreg, natural Treg; Treg, regulatory T cell.

CD40-generated T2 B cells (T2-like Bregs) to syngeneic mice significantly improved renal disease and survival by an IL-10-dependent mechanism. In this model, T2-like Bregs not only suppressed Th1 responses, but induced the differentiation of FoxP3-IL-10+CD4 ${ }^{+} \mathrm{T}$ cells, which could regulate other $\mathrm{CD}^{+} \mathrm{T}$ cells. Interestingly, the therapeutic effect of Breg transfer could be recapitulated by administration of agonistic anti-CD40 [61]. Although the therapeutic use of agonistic anti-CD40 monoclonal antibodies is not a viable therapy for autoimmune diseases, enrichment of Bregs in vitro followed by their transfer might represent a feasible alternative for autoimmune patients who have failed other biological therapies.

Marginal zone B cells have been also proposed as candidates for Bregs in experimental models of rheumatic diseases due to their capacity to up-regulate $\mathrm{IL}-10$ in response to $\mathrm{CpG}$ [62] or after exposure to apoptotic cells [59]. However, it remains to be formally proven whether their IL-10 production is paralleled by functional suppressive capacity. B-1 cells are also known to release IL-10 and IgM natural autoantibody and they have been proposed to play a protective role in individuals predisposed to autoimmunity and in patients with atherosclerosis via enhancing the clearance of apoptotic cells [63-65].

Despite increased interest in Breg biology, the existence of an equivalent population in humans has not yet been fully proven. Populations of IL-10-producing B cells have been identified in healthy individuals as well as in patients with multiple sclerosis [66]. However, their phenotype, suppressive functions and whether they can be exploited for immune therapy of autoimmune disease are the subject of current investigations.

\section{Regulatory dendritic cells}

DCs are mainly regarded as specialized professional antigen presenting cells. In a resting environment, in the absence of any inflammation or pathogenic elements, most DCs are at an immature stage of development, characterized by a high endocytic capacity and low surface expression of major histocompatibility (MHC) and co-stimulatory molecules. In the presence of microbial infections or inflammation, DCs rapidly mature and become activated [67]. The outcome of DC-T cell interactions is regulated by several factors, including the state of DC maturation and/or the presence of cytokines. Immature, or semi-matured DCs with low expression of CD40 and $\mathrm{MHCll}$ can tolerize $\mathrm{T}$ cells and prevent unwanted immune reactions. In the CIA model, stimulation of DCs with TNF $\alpha$ generates DCs with a strong suppressive capacity. Transfer of these TNF $\alpha$-induced DCs suppressed arthritis in recipient syngeneic mice [68]. It is clear that the micro-environmental stimuli that condition DCs are important and numerous strategies based on immunosuppressive agents, such as vitamin-D3, IL-10, TGF $\beta$, glucocorticoids, detaxomethasone, and $\mathrm{N}$-acetyl-I-cysteine, have been used to induce tolerogenic 
DCs $[69,70]$. Amongst them, induction of regulatory DCs via stimulation with vasoactive intestinal peptide (VIP) holds therapeutic promise. Gonzalez-Rey and Delgado have shown that exposure of immature DCs to VIP induces the differentiation of tolerogenic DCs, which efficiently controlled the development of arthritis in an adoptive transfer system [71]. It is possible that maturing DCs exposed in vivo to VIP might differentiate into regulatory DCs that help to keep the regulatory pool 'topped up'.

Regulatory DCs also appear to be the mediators of oral tolerance, a process that refers to the immunological hyporesponsiveness initiated by ingestion of protein antigens [72]. Since oral tolerance is initiated in the gut-associated lymphoid tissue, DCs in the Peyer's Patches are believed to be responsible for priming $\mathrm{CD}_{4}{ }^{+} \mathrm{T}$ cells that secrete IL-10 and IL-4 or TGF $\beta$ in response to oral tolerance regimes; thus, DCs appear to be inducing iTreg ( $\operatorname{Tr} 1$ or Th3) differentiation [73]. Repeated oral administration of Cll to susceptible strains induces tolerance and prevents the induction of CIA, which has been ascribed to a specific subset of DCs that are $\mathrm{CD}_{11 \mathrm{c}^{+}}$and $\mathrm{CD}_{11 \mathrm{~b}^{+}}$[74]. The transfer of Cll-pulsed regulatory DCs prevented arthritis development and promoted the differentiation of IL-10 and/or TGF $\beta$-producing Tregs (Th3) [74-76] Unfortunately, despite positive results in both experimental arthritis and phase II trials, no effect was observed in phase III trials of CII in RA [77]. The possibility of harnessing DCs for the generation of both induced Tregs and adaptive Tr1 cells represents one of the major goals in immunotherapy at the moment as it could potentially replace non-specific immunosuppressive drugs.

\section{Suppressor macrophages}

Macrophages are present at sites of inflammation and have previously been shown to play a pivotal role in the induction and perpetuation of RA [78]. Recently emigrated monocytes mature into macrophages in the RA synovial membrane. Subsets of monocytes differentially colonize the synovial sublining and lining layer as well as the superficial and deep layers of the lining. A possible functional diversity of monocytes in these areas, which is emphasized by the expression of different activation markers and adhesion molecules, is believed to contribute to disease progression [79].

Like many other immune cells, the role of macrophages cannot be simply associated with inflammation, and a distinct subset of macrophages can also act as suppressive cells via immunomodulatory factors, including IL-10, reactive oxygen species (ROS), and tryptophan and arginine catabolism [80-82]. Macrophages can be divided into specific subsets according to functional and phenotypical criteria. 'Classically' activated macrophages are monocytes stimulated with IFN $\gamma$, alone or in combination with IL-12 and IL-23, which differentiate into M1-polarised cells that induce the differentiation of Th1 type responses. Conversely, monocytes activated in the presence of IL-4 and IL-13 differentiate into M2-polarized cells producing IL-10, which favours a Th2 type response [83]. Although not yet extended to arthritis, it is interesting to note that monocytes differentiating in the presence of Tregs acquire a suppressive phenotype and function [84]. Monocytes entering tissues can undergo phenotypic switches between M1 and M2 macrophage phenotypes due to soluble micro-environmental factors (cytokines, chemokines, growth factors, and tissue cells), and the balance of activated Teffs and Tregs affects their maturation [85]. In addition, macrophages differentiating upon stimulation with macrophage colony-stimulating factor express indoleamine 2,3-dioygenase and inhibit $\mathrm{T}$ cell proliferation in vitro by depleting the important amino acid tryptophan from co-cultures in response to $T$ cell activation [86]. The adoptive transfer of in vitro TGF $\beta$-generated antigen presenting $\mathrm{F} 4 / 80^{+}$peritoneal macrophages induced the differentiation of TGF $\beta$-producing Tregs in primed and naïve mice. Interestingly, whereas in naive mice the majority of induced Tregs were $\mathrm{CD}^{+}$and produced TGF $\beta$, in primed mice the induced Tregs were $\mathrm{CD}^{+}$Tregs and the response involved Fas-mediated deletion of Teffs [87]. Macrophages derived from myeloid suppressor cells from tumour-bearing mice and cancer patients could suppress $\mathrm{T}$ cell proliferation in vitro and induce the differentiation of FoxP3 ${ }^{+}$Tregs in vivo using IL-10/IFN $\gamma$ dependent mechanisms [88]. In humans, monocyte-derived macrophages can convert $\mathrm{CD}^{+}{ }^{+}$naïve $\mathrm{T}$ cells, but not activated $\mathrm{T}$ cells, into Tregs, suggesting that macrophages might curb immune responses during tolerogenic conditions but not during inflammation [89].

In the context of arthritis, it has been shown that macrophages control disease development via ROS. Mice with a mutation in the neutrophil cytosolic factor 1 (Ncf1) gene develop exacerbated arthritis, an enhanced IgG response and delayed-type hypersensitivity responses against Cll [90]. Further work by the same group demonstrated that resistance to the disease relies upon the ROS produced by macrophages. Transgenic mice over-expressing functional Ncf1 in macrophages develop a significantly milder disease compared to wild-type mice and suppress $T$ cell responses during antigen presentation [91]. Interestingly, whilst a significant reduction of IL-2 and proliferation was observed, the levels of IFN $\gamma$ remained unchanged despite the reduced severity of the disease. Unequivocally, these studies challenge the common dogma that antioxidants are anti-inflammatory and provide an additional class of drugs with strong potential as therapeutics [92].

\section{Conclusion}

Our findings and those from others challenge the paradigm of Tregs as the sole co-ordinating cell type directly involved in the regulation of autoimmunity. Further study is needed to understand the interaction between different immunoregulatory cells and unravel the outcomes of these interactions. A more cohesive approach aimed at the expansion of multiple regulatory cells could be the key to designing better therapies 
for RA. The interpretation of the collective data discussed in this review suggests that therapies aimed at drastically depleting or entirely eliminating $\mathrm{T}$ or $\mathrm{B}$ cells from patients with autoimmunity need to be carefully re-evaluated, since the depletion of regulatory subsets could have long-lasting deleterious effects.

\section{Outstanding questions}

It is well documented that deletion of $\mathrm{FoxP}^{+}$cells either in adult or neonatal mice can cause catastrophic autoimmunity [93] and FoxP3 mutations in humans cause lethal diseases $[94,95]$. Recent data have shown that the ablation of all DCs, although not only those with regulatory functions, leads to development of autoimmunity, which was, however, much milder than the aggressive rapidly fatal disease that occurs when Foxp $3^{+}$Tregs are deleted [96]. However, although it remains to be revealed whether the selective deletion of regulatory $B$ cells, DCs or macrophages also leads to the development of severe forms of autoimmunity, until then regulatory $\mathrm{T}$ cells should be placed at the top of the putative 'regulatory pyramid'.

\section{Acknowledgements}

We would like to acknowledge Drs Paul Blair and Clare Notley for their critical evaluation of this manuscript. NC and our work are funded by the Arthritis Research Campaign (ARC) Programme grant MP/17707 to $\mathrm{CM}$.

\section{Competing interests}

The authors declare that they have no competing interests.

\section{References}

1. Feldmann M, Brennan FM, Maini RN: Rheumatoid arthritis. Cell 1996, 85:307-310.

2. Murphy G, Nagase $\mathrm{H}$ : Reappraising metalloproteinases in rheumatoid arthritis and osteoarthritis: destruction or repair? Nat Clin Pract Rheumatol 2008, 4:128-135.

3. Feldmann M, Brennan FM, Maini RN: Role of cytokines in rheumatoid arthritis. Annu Rev Immunol 1996, 14:397-440.

4. Rudensky AY, Gavin M, Zheng Y: FOXP3 and NFAT: partners in tolerance. Cell 2006, 126:253-256.

5. Thornton AM, Shevach EM: Suppressor effector function of CD4+CD25+ immunoregulatory $\mathrm{T}$ cells is antigen nonspecific. $\mathrm{J}$ Immuno/ 2000, 164:183-190.

6. Dieckmann D, Plottner H, Berchtold S, Berger T, Schuler G: Ex vivo isolation and characterization of CD4(+)CD25(+) T cells with regulatory properties from human blood. J Exp Med 2001, 193:1303-1310.

7. Horwitz DA, Zheng SG, Gray JD: Natural and TGF-beta-induced Foxp3(+)CD4(+) CD25(+) regulatory T cells are not mirror images of each other. Trends Immunol 2008, 29:429-435.

8. Nocentini G, Riccardi C: GITR: a multifaceted regulator of immunity belonging to the tumor necrosis factor receptor superfamily. Eur J Immunol 2005, 35:1016-1022.

9. Sarris M, Andersen KG, Randow F, Mayr L, Betz AG: Neuropilin1 expression on regulatory $T$ cells enhances their interactions with dendritic cells during antigen recognition. Immunity 2008, 28:402-413.

10. Thornton AM, Donovan EE, Piccirillo CA, Shevach EM: Cutting edge: IL-2 is critically required for the in vitro activation of CD4+CD25+ T cell suppressor function. J Immuno/ 2004, 172: 6519-6523.

11. Andersson J, Tran DQ, Pesu M, Davidson TS, Ramsey H, O'Shea JJ, Shevach EM: CD4+ FoxP3+ regulatory T cells confer infectious tolerance in a TGF-beta-dependent manner. $J$ Exp Med 2008, 205:1975-1981.
12. Annacker $\mathrm{O}$, Pimenta-Araujo $\mathrm{R}$, Burlen-Defranoux $\mathrm{O}$, Barbosa TC, Cumano $A$, Bandeira $A: C D 25+C D 4+T$ cells regulate the expansion of peripheral CD4 T cells through the production of IL-10. J Immuno/ 2001, 166:3008-3018.

13. Collison LW, Workman CJ, Kuo TT, Boyd K, Wang Y, Vignali KM, Cross R, Sehy D, Blumberg RS, Vignali DA: The inhibitory cytokine IL-35 contributes to regulatory T-cell function. Nature 2007, 450:566-569.

14. Chen W, Jin W, Hardegen N, Lei KJ, Li L, Marinos N, McGrady G, Wahl SM: Conversion of peripheral CD4+CD25- naive T cells to CD4+CD25+ regulatory T cells by TGF-beta induction of transcription factor Foxp3. J Exp Med 2003, 198:1875-1886.

15. Battaglia M, Stabilini A, Draghici E, Migliavacca B, Gregori S, Bonifacio $E$, Roncarolo MG: Induction of tolerance in type 1 diabetes via both CD4+CD25+ $T$ regulatory cells and $T$ regulatory type 1 cells. Diabetes 2006, 55:1571-1580.

16. Bynoe MS, Evans JT, Viret C, Janeway CA Jr: Epicutaneous immunization with autoantigenic peptides induces T suppressor cells that prevent experimental allergic encephalomyelitis. Immunity 2003, 19:317-328.

17. Haribhai D, Lin W, Edwards B, Ziegelbauer J, Salzman NH, Carlson MR, Li SH, Simpson PM, Chatila TA, Williams CB: A central role for induced regulatory $\mathrm{T}$ cells in tolerance induction in experimental colitis. J Immunol 2009, 182:3461-3468.

18. Sakaguchi S, Takahashi T, Nishizuka Y: Study on cellular events in post-thymectomy autoimmune oophoritis in mice. II. Requirement of Lyt-1 cells in normal female mice for the prevention of oophoritis. J Exp Med 1982, 156:1577-1586.

19. Mold JE, Michaelsson J, Burt TD, Muench MO, Beckerman KP, Busch MP, Lee TH, Nixon DF, McCune JM: Maternal alloantigens promote the development of tolerogenic fetal regulatory T cells in utero. Science 2008, 322:1562-1565.

20. Radulovic S, Jacobson MR, Durham SR, Nouri-Aria KT: Grass pollen immunotherapy induces Foxp3-expressing CD4+ CD25+ cells in the nasal mucosa. J Allergy Clin Immunol 2008, 121:1467-1472, 1472.e1.

21. Groux H, O'Garra A, Bigler M, Rouleau M, Antonenko S, de Vries JE, Roncarolo MG: A CD4+ T-cell subset inhibits antigen-specific T-cell responses and prevents colitis. Nature 1997, 389: 737-742.

22. Vieira PL, Christensen JR, Minaee S, O'Neill EJ, Barrat FJ, Boonstra A, Barthlott T, Stockinger B, Wraith DC, O'Garra A: IL-10secreting regulatory $T$ cells do not express Foxp 3 but have comparable regulatory function to naturally occurring CD4+CD25+ regulatory T cells. J Immunol 2004, 172:59865993.

23. Cottrez F, Hurst SD, Coffman RL, Groux H: T regulatory cells 1 inhibit a Th2-specific response in vivo. J Immunol 2000, 165: 4848-4853.

24. Bacchetta R, Gregori S, Roncarolo MG: CD4+ regulatory T cells: mechanisms of induction and effector function. Autoimmun Rev 2005, 4:491-496.

25. Levings MK, Gregori S, Tresoldi E, Cazzaniga S, Bonini C, Roncarolo MG: Differentiation of Tr1 cells by immature dendritic cells requires IL-10 but not CD25+CD4+ Tr cells. Blood 2005, 105:1162-1169.

26. Faria $\mathrm{AM}$, Weiner HL: Oral tolerance: therapeutic implications for autoimmune diseases. Clin Dev Immunol 2006, 13:143157.

27. Chen Y, Kuchroo VK, Inobe J, Hafler DA, Weiner HL: Regulatory $\mathrm{T}$ cell clones induced by oral tolerance: suppression of autoimmune encephalomyelitis. Science 1994, 265:12371240.

28. Faria AM, Weiner HL: Oral tolerance. Immunol Rev 2005, 206: 232-259.

29. Ishikawa $H$, Ochi $H$, Chen ML, Frenkel D, Maron R, Weiner HL: Inhibition of autoimmune diabetes by oral administration of anti-CD3 monoclonal antibody. Diabetes 2007, 56:2103-2109.

30. Smith TR, Kumar V: Revival of CD8+ Treg-mediated suppression. Trends Immuno/ 2008, 29:337-342.

31. Bendelac A, Savage PB, Teyton L: The biology of NKT cells. Annu Rev Immunol 2007, 25:297-336.

32. Hayday A, Tigelaar R: Immunoregulation in the tissues by gammadelta T cells. Nat Rev Immunol 2003, 3:233-242.

33. Morgan ME, Sutmuller RP, Witteveen HJ, van Duivenvoorde LM Zanelli E, Melief CJ, Snijders A, Offringa R, de Vries RR, Toes RE: CD25+ cell depletion hastens the onset of severe disease in 
collagen-induced arthritis. Arthritis Rheum 2003, 48:14521460 .

34. Morgan ME, Flierman R, van Duivenvoorde LM, Witteveen $\mathrm{HJ}$, van Ewijk W, van Laar JM, de Vries RR, Toes RE: Effective treatment of collagen-induced arthritis by adoptive transfer of CD25+ regulatory T cells. Arthritis Rheum 2005, 52:2212-2221.

35. Mauri C, Ehrenstein MR: The 'short' history of regulatory B cells. Trends Immuno/ 2008, 29:34-40.

36. Fontenot JD, Rasmussen JP, Gavin MA, Rudensky AY: A function for interleukin 2 in Foxp3-expressing regulatory $\mathrm{T}$ cells. Nat Immunol 2005, 6:1142-1151.

37. Nolte-'t Hoen EN, Boot EP, Wagenaar-Hilbers JP, van Bilsen JH, Arkesteijn GJ, Storm G, Everse LA, van Eden W, Wauben MH: Identification and monitoring of effector and regulatory $T$ cells during experimental arthritis based on differential expression of CD25 and CD134. J Leukoc Biol 2008, 83:112-121.

38. Banham AH, Powrie FM, Suri-Payer E: FOXP3+ regulatory T cells: Current controversies and future perspectives. Eur $J$ Immunol 2006, 36:2832-2836.

39. Ehrenstein MR, Evans JG, Singh A, Moore S, Warnes G, Isenberg $D A$, Mauri C: Compromised function of regulatory $T$ cells in rheumatoid arthritis and reversal by anti-TNFalpha therapy. $J$ Exp Med 2004, 200:277-285.

40. Valencia X, Stephens G, Goldbach-Mansky R, Wilson M, Shevach EM, Lipsky PE: TNF downmodulates the function of human CD4+CD25hi T-regulatory cells. Blood 2006, 108:253-261.

41. van Amelsfort JM, van Roon JA, Noordegraaf M, Jacobs KM, Bijlsma JW, Lafeber FP, Taams LS: Proinflammatory mediatorinduced reversal of CD4+,CD25+ regulatory T cell-mediated suppression in rheumatoid arthritis. Arthritis Rheum 2007, 56: 732-742.

42. Jacob CO, Aiso S, Michie SA, McDevitt HO, Acha-Orbea H: Prevention of diabetes in nonobese diabetic mice by tumor necrosis factor (TNF): similarities between TNF-alpha and interleukin 1. Proc Natl Acad Sci USA 1990, 87:968-972.

43. Jacob CO, McDevitt HO: Tumour necrosis factor-alpha in murine autoimmune 'lupus' nephritis. Nature 1988, 331:356358.

44. Chen X, Subleski JJ, Kopf H, Howard OM, Mannel DN, Oppenheim JJ: Cutting edge: expression of TNFR2 defines a maximally suppressive subset of mouse CD4+CD25+FoxP3+ T regulatory cells: applicability to tumor-infiltrating $\mathrm{T}$ regulatory cells. J Immunol 2008, 180:6467-6471.

45. Aringer M, Smolen JS: The role of tumor necrosis factor-alpha in systemic lupus erythematosus. Arthritis Res Ther 2008, 10: 202.

46. van Amelsfort JM, Jacobs KM, Biilsma JW, Lafeber FP, Taams LS: CD4(+)CD25(+) regulatory T cells in rheumatoid arthritis: differences in the presence, phenotype, and function between peripheral blood and synovial fluid. Arthritis Rheum 2004, 50: 2775-2785.

47. Cao D, van Vollenhoven R, Klareskog L, Trollmo C, Malmstrom V: CD25brightCD4+ regulatory $T$ cells are enriched in inflamed joints of patients with chronic rheumatic disease. Arthritis Res Ther 2004, 6:R335-346.

48. Lubberts $\mathrm{E}$, Koenders Ml, van den Berg WB: The role of T-cell interleukin-17 in conducting destructive arthritis: lessons from animal models. Arthritis Res Ther 2005, 7:29-37.

49. Garrett-Sinha LA, John S, Gaffen SL: IL-17 and the Th17 lineage in systemic lupus erythematosus. Curr Opin Rheumatol 2008, 20:519-525.

50. Nakae S, Nambu A, Sudo K, Iwakura Y: Suppression of immune induction of collagen-induced arthritis in IL-17-deficient mice. $\mathrm{J}$ Immuno/ 2003, 171:6173-6177.

51. Park $\mathrm{H}, \mathrm{Li} Z$, Yang $X \mathrm{X}$, Chang $\mathrm{SH}$, Nurieva $\mathrm{R}$, Wang $\mathrm{YH}$, Wang $\mathrm{Y}$, Hood L, Zhu Z, Tian Q, Dong C: A distinct lineage of CD4 T cells regulates tissue inflammation by producing interleukin 17. Nat Immunol 2005, 6:1133-1141.

52. Nistala $K$, Moncrieffe $H$, Newton KR, Varsani $H$, Hunter $P$, Wedderburn LR: Interleukin-17-producing $T$ cells are enriched in the joints of children with arthritis, but have a reciprocal relationship to regulatory T cell numbers. Arthritis Rheum 2008, 58:875-887.

53. Katsikis PD, Chu CQ, Brennan FM, Maini RN, Feldmann M: Immunoregulatory role of interleukin 10 in rheumatoid arthritis. J Exp Med 1994, 179:1517-1527.

54. Bouaziz JD, Yanaba K, Tedder TF: Regulatory B cells as inhibitors of immune responses and inflammation. Immunol Rev 2008, 224:201-214.

55. Wolf SD, Dittel BN, Hardardottir F, Janeway CA Jr: Experimental autoimmune encephalomyelitis induction in genetically $B$ celldeficient mice. J Exp Med 1996, 184:2271-2278.

56. Fillatreau S, Sweenie CH, McGeachy MJ, Gray D, Anderton SM: B cells regulate autoimmunity by provision of IL-10. Nat Immunol 2002, 3:944-950.

57. Mauri C, Gray D, Mushtaq N, Londei M: Prevention of arthritis by interleukin 10-producing B cells. J Exp Med 2003, 197:489501.

58. Lenert $P$, Brummel R, Field EH, Ashman RF: TLR-9 activation of marginal zone $B$ cells in lupus mice regulates immunity through increased IL-10 production. J Clin Immuno/ 2005, 25: 29-40.

59. Gray M, Miles K, Salter D, Gray D, Savill J: Apoptotic cells protect mice from autoimmune inflammation by the induction of regulatory B cells. Proc Natl Acad Sci USA 2007, 104: 14080-14085

60. Evans JG, Chavez-Rueda KA, Eddaoudi A, Meyer-Bahlburg A, Rawlings DJ, Ehrenstein MR, Mauri C: Novel suppressive function of transitional 2 B cells in experimental arthritis. J Immunol 2007, 178:7868-7878.

61. Blair PA, Chavez-Rueda KA, Evans JG, Shlomchik MJ, Eddaoudi A, Isenberg DA, Ehrenstein MR, Mauri C: Selective targeting of $B$ cells with agonistic anti-CD40 is an efficacious strategy for the generation of induced regulatory T2-like B cells and for the suppression of lupus in MRL/lpr mice. J Immuno/ 2009, 182:3492-3502

62. Brummel R, Lenert P: Activation of marginal zone $B$ cells from lupus mice with type $A(D)$ CpG-oligodeoxynucleotides. J Immunol 2005, 174:2429-2434.

63. Carroll MC, Prodeus AP: Linkages of innate and adaptive immunity. Curr Opin Immunol 1998, 10:36-40.

64. Silverman GJ, Srikrishnan R, Germar K, Goodyear CS, Andrews KA, Ginzler EM, Tsao BP: Genetic imprinting of autoantibody repertoires in systemic lupus erythematosus patients. Clin Exp Immunol 2008, 153:102-116.

65. Binder CJ, Horkko S, Dewan A, Chang MK, Kieu EP, Goodyear CS, Shaw PX, Palinski W, Witztum JL, Silverman GJ: Pneumococcal vaccination decreases atherosclerotic lesion formation: molecular mimicry between Streptococcus pneumoniae and oxidized LDL. Nat Med 2003, 9:736-743.

66. Correale J, Farez M, Razzitte G: Helminth infections associated with multiple sclerosis induce regulatory B cells. Ann Neurol 2008, 64:187-199.

67. Cella M, Sallusto F, Lanzavecchia A: Origin, maturation and antigen presenting function of dendritic cells. Curr Opin Immunol 1997, 9:10-16.

68. van Duivenvoorde LM, Louis-Plence P, Apparailly F, van der Voort El, Huizinga TW, Jorgensen C, Toes RE: Antigen-specific immunomodulation of collagen-induced arthritis with tumor necrosis factor-stimulated dendritic cells. Arthritis Rheum 2004, 50:3354-3364.

69. Morelli $A E$, Thomson AW: Tolerogenic dendritic cells and the quest for transplant tolerance. Nat Rev Immunol 2007, 7:610621.

70. van Duivenvoorde LM, Han WG, Bakker AM, Louis-Plence $P$, Charbonnier LM, Apparailly F, van der Voort El, Jorgensen C, Huizinga TW, Toes RE: Immunomodulatory dendritic cells inhibit Th1 responses and arthritis via different mechanisms. $J$ Immunol 2007, 179:1506-1515.

71. Gonzalez-Rey E, Delgado M: Role of vasoactive intestinal peptide in inflammation and autoimmunity. Curr Opin Investig Drugs 2005, 6:1116-1123.

72. Strobel S, Mowat AM: Immune responses to dietary antigens: oral tolerance. Immunol Today 1998, 19:173-181.

73. Weiner HL: The mucosal milieu creates tolerogenic dendritic cells and $\mathrm{T}(\mathrm{R}) \mathbf{1}$ and $\mathrm{T}(\mathrm{H}) \mathbf{3}$ regulatory cells. Nat Immuno/ 2001 , 2:671-672.

74. Alvarado-Sanchez B, Hernandez-Castro B, Portales-Perez D, Baranda L, Layseca-Espinosa E, Abud-Mendoza C, CubillasTejeda AC, Gonzalez-Amaro R: Regulatory T cells in patients with systemic lupus erythematosus. J Autoimmun 2006, 27: 110-118.

75. Khare SD, Krco CJ, Griffiths MM, Luthra HS, David CS: Oral administration of an immunodominant human collagen 
peptide modulates collagen-induced arthritis. J Immunol 1995, 155:3653-3659.

76. Thompson HS, Staines NA: Gastric administration of type II collagen delays the onset and severity of collagen-induced arthritis in rats. Clin Exp Immunol 1986, 64:581-586.

77. Choy EH, Scott DL, Kingsley GH, Thomas S, Murphy AG, Staines $\mathrm{N}$, Panayi GS: Control of rheumatoid arthritis by oral tolerance. Arthritis Rheum 2001, 44:1993-1997.

78. Kinne RW, Stuhlmuller B, Burmester GR: Cells of the synovium in rheumatoid arthritis. Macrophages. Arthritis Res Ther 2007, 9:224.

79. Cutolo M, Sulli A, Barone A, Seriolo B, Accardo S: Macrophages, synovial tissue and rheumatoid arthritis. Clin Exp Rheumatol 1993, 11:331-339.

80. Gelderman KA, Hultqvist M, Olsson LM, Bauer K, Pizzolla A, Olofsson P, Holmdahl R: Rheumatoid arthritis: the role of reactive oxygen species in disease development and therapeutic strategies. Antioxid Redox Signal 2007, 9:1541-1567.

81. Hultqvist M, Backlund J, Bauer K, Gelderman KA, Holmdahl R: Lack of reactive oxygen species breaks $T$ cell tolerance to collagen type II and allows development of arthritis in mice. J Immunol 2007, 179:1431-1437.

82. Szekanecz $Z$, Koch $A E$ : Macrophages and their products in rheumatoid arthritis. Curr Opin Rheumatol 2007, 19:289-295.

83. Martinez FO, Sica A, Mantovani A, Locati M: Macrophage activation and polarization. Front Biosci 2008, 13:453-461.

84. Tiemessen MM, Jagger AL, Evans HG, van Herwijnen MJ, John S, Taams LS: CD4+CD25+Foxp3+ regulatory T cells induce alternative activation of human monocytes/macrophages. Proc Natl Acad Sci USA 2007, 104:19446-19451.

85. Winston BW, Krein PM, Mowat C, Huang Y: Cytokine-induced macrophage differentiation: a tale of 2 genes. Clin Invest Med 1999, 22:236-255

86. Munn DH, Shafizadeh E, Attwood JT, Bondarev I, Pashine A, Mellor AL: Inhibition of T cell proliferation by macrophage tryptophan catabolism. J Exp Med 1999, 189:1363-1372.

87. Alard P, Clark SL, Kosiewicz MM: Mechanisms of tolerance induced by TGF beta-treated APC: CD4 regulatory T cells prevent the induction of the immune response possibly through a mechanism involving TGF beta. Eur J Immunol 2004, 34:1021-1030.

88. Lin HH, Faunce DE, Stacey M, Terajewicz A, Nakamura T, ZhangHoover J, Kerley M, Mucenski ML, Gordon S, Stein-Streilein J: The macrophage $F 4 / 80$ receptor is required for the induction of antigen-specific efferent regulatory $\mathrm{T}$ cells in peripheral tolerance. J Exp Med 2005, 201:1615-1625.

89. Hoves S, Krause SW, Schutz C, Halbritter D, Scholmerich J, Herfarth $\mathrm{H}$, Fleck $\mathrm{M}$ : Monocyte-derived human macrophages mediate anergy in allogeneic $T$ cells and induce regulatory $T$ cells. J Immuno/ 2006, 177:2691-2698.

90. Hultqvist M, Olofsson P, Holmberg J, Backstrom BT, Tordsson J, Holmdahl R: Enhanced autoimmunity, arthritis, and encephalomyelitis in mice with a reduced oxidative burst due to a mutation in the Ncf1 gene. Proc Natl Acad Sci USA 2004, 101:12646-12651.

91. Gelderman KA, Hultqvist M, Pizzolla A, Zhao M, Nandakumar KS, Mattsson R, Holmdahl R: Macrophages suppress $T$ cell responses and arthritis development in mice by producing reactive oxygen species. J Clin Invest 2007, 117:3020-3028.

92. Hultqvist M, Olofsson P, Gelderman KA, Holmberg J, Holmdahl R: A new arthritis therapy with oxidative burst inducers. PLoS Med 2006, 3:e348.

93. Kim JM, Rasmussen JP, Rudensky AY: Regulatory T cells prevent catastrophic autoimmunity throughout the lifespan of mice. Nat Immunol 2007, 8:191-197.

94. Bennett CL, Christie J, Ramsdell F, Brunkow ME, Ferguson PJ, Whitesell L, Kelly TE, Saulsbury FT, Chance PF, Ochs HD: The immune dysregulation, polyendocrinopathy, enteropathy, Xlinked syndrome (IPEX) is caused by mutations of FOXP3. Nat Genet 2001, 27:20-21.

95. Wildin RS, Ramsdell F, Peake J, Faravelli F, Casanova JL, Buist N, Levy-Lahad E, Mazzella M, Goulet O, Perroni L, Bricarelli FD, Byrne G, McEuen M, Proll S, Appleby M, Brunkow ME: X-linked neonatal diabetes mellitus, enteropathy and endocrinopathy syndrome is the human equivalent of mouse scurfy. Nat Genet 2001, 27:18-20.

96 Ohnmacht C, Pullner A, King S, Drexler I, Meier S, Brocker T,
Voehringer D: Constitutive ablation of dendritic cells breaks self-tolerance of CD4 T cells and results in spontaneous fatal autoimmunity. J Exp Med 2009, 206:549-559. 